\title{
Phylogenesis of Relapsing Fever Borrelia spp.
}

\author{
N. MARTI RAS, ${ }^{1}$ B. LASCOLA, ${ }^{2}$ D. POSTIC,${ }^{1 *}$ S. J. CUTLER,${ }^{3}$ F. RODHAIN,${ }^{4}$ \\ G. BARANTON, ${ }^{1}$ AND D. RAOULT ${ }^{2}$ \\ Unité de Bactériologie Moléculaire et Médicale and Unité d'Ecologie des Systèmes Vectoriels, ${ }^{4}$ Institut Pasteur, \\ 75724 Paris Cedex 15, and Unité des Rickettsies, Centre National de la Recherche Scientifique EP J 0054 \\ Faculté de la Timone, Marseille, ${ }^{2}$ France, and Department of Medical Microbiology, \\ Charing Cross and Westminster Medical School, London, United Kingdom ${ }^{3}$
}

\begin{abstract}
The phylogenetic relationships of 20 relapsing fever (RF) Borrelia spp. were estimated on the basis of the sequences of $\boldsymbol{r} r$ genes. Complete sequences were aligned and compared with previously published sequences, and the similarity values were found to be 97.7 to $99.9 \%$. Phylogenetic trees were constructed by using the three neighbor-joining, maximum-parsimony, and maximum-likelihood methods. The results of the comparative phylogenetic analysis divided the RF Borrelia spp. into three major clusters. One cluster included Borrelia crocidurae, Borrelia duttonii, Borrelia recurrentis, and Borrelia hispanica. Another cluster comprised two main branches with Borrelia coriaceae, Borrelia lonestari, and Borrelia miyamotoi on one side and Borrelia parkeri, Borrelia turicatae, and Borrelia hermsii on the other side. Borrelia anserina constituted the third cluster. The phylogenetic position of Borrelia persica was more uncertain. These results suggested that the taxonomy of these spirochetes should be revised. To overcome the problems of culturing the spirochetes, RF Borrelia primers were defined. Following PCR amplification of the rrs gene, restriction length fragment polymorphism could be used to distinguish between RF Borrelia strains.
\end{abstract}

The genus Borrelia comprises the arthropod vector-transmissible spirochetes. These organisms are responsible for two groups of human disease: lyme borreliosis, which is transmitted by the hard Ixodes ticks (6), and relapsing fevers (RF), most of which are transmitted by soft ticks (Argasidae) (the exception is louse-borne RF, which is transmitted by Pediculus humanus) $(5,10,24,30)$.

Usually, when strictly parasitic organisms have been considered, their taxonomy has been based on the cospeciation concept. However, this does not apply to Borrelia burgdorferi sensu lato, since DNA-DNA reassociation studies have shown that $B$. burgdorferi sensu lato constitutes a complex of at least eight genomospecies (28), including five species which have been named $(2,7,18,21)$. The members of this complex have a broad spectrum of hosts and do not exhibit specific associations with vector species (for instance, B. burgdorferi sensu stricto can be transmitted by both Ixodes scapularis [formerly Ixodes dammini] and Loodes ricinus, and the latter tick is also able to transmit Borrelia garinii, Borrelia afzelii, and genomic groups PotiB2 and VS116).

RF-associated Borrelia species have been named on the basis of the cospeciation concept, taking into account the geographic endemicity of the vectors. Some of these organisms have a worldwide distribution: Borrelia recurrentis is transmitted by human body lice (10), and Borrelia anserina is restricted to birds and Argas ticks. Other species are geographically restricted. The specificity of the association between Borrelia species and vectors has been questioned, as Borrelia duttonii, Borrelia crocidurae, and Borrelia hispanica, which are naturally transmitted in nature by Ornithodoros moubata, Ornithodoros sonrai (formerly Ornithodoros erraticus sonrai), and Ornithodoros erraticus (formerly Ornithodoros erraticus erraticus), respectively, could be experimentally adapted to lice (10). These RF Borrelia species have fastidious cultural requirements, and nei-

\footnotetext{
* Corresponding author. Mailing address: Unité de Bactériologie Moléculaire et Médicale, Institut Pasteur, 28 rue du Docteur Roux, 75724 Paris Cedex 15, France. Phone: 331456883 37. Fax: 3314061 30 01. Electronic mail address: dpostic@pasteur.fr.
}

ther phenotypic characteristics nor genomic data (from DNADNA reassociation studies) are available for them, although cultivation of a strain of $B$. recurrentis was recently reported by Cutler et al. (9). In contrast, Borrelia hermsii, Borrelia turicatae, and Borrelia parkeri are easily cultivable. Characterization of RF Borrelia species by serotyping is not possible because of the phenomenon of antigenic variation $(23,27)$. To date, crossimmunity trials and the use of animal models have been the only methods for clarifying the identities of isolates (32). Taxonomic studies have not been possible previously.

Recently, the following new Borrelia species have been isolated from hard ticks: Borrelia miyamotoi, which was isolated from both Ixodes persulcatus and rodents in Japan (13); and Borrelia lonestari, which was isolated from Amblyomma americanum in the United States (4). Despite the association of these two Borrelia species with hard ticks, their $r$ s sequences appear to be more similar to the previously available RF Borrelia rrs sequences than $B$. burgdorferi sensu lato sequences are (4).

To study the phylogenetic relationships of RF Borrelia species, we sequenced the $r$ rs genes from a variety of isolates. On the basis of the sequences obtained and restriction fragment length polymorphism profiles of PCR products, we were able to genetically identify RF Borrelia species.

\section{MATERIALS AND METHODS}

Culture. The RF Borrelia strains used in this study are listed in Table 1. $B$. hermsii, B. parkeri, B. turicatae, B. coriaceae, B. anserina, and B. recurrentis were grown in BSK II medium at $30^{\circ} \mathrm{C}$ (3).

Animal passages. All strains of $B$. crocidurae and $B$. duttonii were maintained by serial passage in 10-week-old female Swiss mice (obtained from IFFACREDO) weighing 28 to $30 \mathrm{~g}$. The mice were inoculated intraperitoneally with 0.3 to $0.4 \mathrm{ml}$ of infected blood preserved in liquid nitrogen with $10 \%$ dimethyl sulfoxide or with infected brain tissue from a mouse inoculated 1 month or more earlier. Spirochete counts were determined daily by using dark-field microscopy, until the optimal bacterial concentration was reached. The maximal yield of organisms, $10^{6}$ to $10^{7}$ organisms per $\mathrm{ml}$ of blood, was usually achieved 3 days after inoculation of infected blood or 6 days after inoculation of infected brain tissue. The animals were anesthetized with pentobarbital and bled immediately by puncture of the vena cava.

$B$. hispanica and Borrelia persica strains were maintained by passage in male guinea pigs (obtained from IFFA-CREDO) weighing 300 to $350 \mathrm{~g}$. The animals were inoculated with 0.4 to $0.5 \mathrm{ml}$ of infected blood preserved in liquid nitrogen 
TABLE 1. Sources and nucleotide sequence accession numbers of RF Borrelia strains used in this study

\begin{tabular}{|c|c|c|c|c|}
\hline Species & Strain & Source & $\begin{array}{l}\text { Geographic origin } \\
\text { (date of isolation) }\end{array}$ & $\begin{array}{c}\text { GenBank } \\
\text { accession no. }\end{array}$ \\
\hline B. hermsii & $\mathrm{HS}^{\mathrm{T}}\left(=\right.$ ATCC $\left.35209^{\mathrm{T}}\right)$ & Ornithodoros hermsi & United States & U42292 \\
\hline B. parkeri & M3001 & Ornithodoros parkeri & United States & U42296 \\
\hline B. turicatae & M2007 & Ornithodoros turicata & United States & U42299 \\
\hline B. anserina & ES-1 & Argas persicus & & U42284 \\
\hline B. coriaceae & $\operatorname{Co53^{\mathrm {T}}}\left(=\operatorname{ATCC} 43381^{\mathrm{T}}\right)$ & Ormithodoros coriaceus & United States & U42286 \\
\hline B. recurrentis & A1 & Human blood & Ethiopia & $\mathrm{U} 42300$ \\
\hline B. persica & UESV/340 & Omithodoros tholozani & Iran (1974) & U42297 \\
\hline B. hispanica & $\mathrm{UESV} / 246$ & Ornithodoros erraticus & Morocco & U42294 \\
\hline \multirow[t]{9}{*}{ B. crocidurae } & UESV/ACH & Ornithodoros sonrai & Mauritania (1968) & $\mathrm{U} 42283$ \\
\hline & UESV/626BAN & Ornithodoros sonrai & Senegal (1978) & U42285 \\
\hline & UESV/917BAR & Human blood & Mali (1988) & U42287 \\
\hline & UESV/1040DAK 24 & Mastomys erythroleucus & Senegal (1989) & U42289 \\
\hline & UESV/1043DAK 28 & Mastomys erythroleucus & Senegal (1989) & $\mathrm{U} 42295$ \\
\hline & UESV/1045DAK 33 & Mastomys erythroleucus & Senegal (1989) & U42290 \\
\hline & UESV/MER & Ornithodoros sonrai & Morocco & U42291 \\
\hline & UESV/523SIS & Human blood & Mali (1977) & U42301 \\
\hline & UESV/1096TEN & Human blood & Senegal (1991) & U42302 \\
\hline \multirow[t]{3}{*}{ B. duttonii } & UESV/117DUTT & Ornithodoros moubata & Zaire (1949) & U42288 \\
\hline & UESV/334RWA & Ornithodoros moubata & Rwanda (1975) & U42298 \\
\hline & UR/BD94MIT & Ornithodoros moubata & Zaire (1994) & U42293 \\
\hline
\end{tabular}

with $10 \%$ dimethyl sulfoxide. Blood was removed by intracardiac puncture approximately 3 days after infection by $B$. persica and 4 days after infection by $B$. hispanica.

When growth levels were low, multiple passages were required to reach the optimal concentration. Heparin, which interferes with the PCR (16), was avoided when infected blood samples were collected. Therefore, blood was allowed to clot, and the serum was separated by centrifugation and used for PCR experiments.

DNA preparation. DNAs from noncultivable RF Borrelia strains were extracted from $200 \mu \mathrm{l}$ of serum by using a QIA ampBlood kit (Qiagen) according to the manufacturer's instructions.

Portions ( $2 \mathrm{ml}$ ) of cultures of B. hermsii, B. turicatae, B. parkeri, B. anserina, B. coriaceae, and $B$. burgdorferi sensu lato were centrifuged at $10,000 \mathrm{rpm}$, and the resulting pellets were washed in phosphate-buffered saline and resuspended in $100 \mu \mathrm{l}$ of distilled water before the preparations were boiled at $95^{\circ} \mathrm{C}$ for $10 \mathrm{~min}$
These suspensions were stored at $-20^{\circ} \mathrm{C}$ until they were used for PCR experiments.

DNA from $B$, recurrentis was phenol extracted. Cells harvested from BSK II medium were incubated for $3 \mathrm{~h}$ at $56^{\circ} \mathrm{C}$ in lysis buffer containing $10 \mathrm{mM}$ Tris $(\mathrm{pH}$ 8 ), $60 \mathrm{mM}$ EDTA ( $\mathrm{pH} 8$ ), $5 \%$ sodium dodecyl sulfate, and $50 \mu \mathrm{g}$ of proteinase $\mathrm{K}$ per ml. DNA was phenol extracted, ethanol precipitated, and resuspended in distilled water. Following a $30-\mathrm{min}$ incubation at $37^{\circ} \mathrm{C}$ with RNase $\mathrm{A}(2 \mu \mathrm{g} / \mathrm{ml})$, the DNA was again ethanol precipitated and resuspended in water, and then it was stored at $-20^{\circ} \mathrm{C}$ until it was used.

PCR methods. All of the primer sets used in this study are listed in Table 2. Each PCR mixture $(50 \mu \mathrm{l})$ contained $5 \mu \mathrm{l}$ of heated bacterial suspension or $5 \mathrm{ng}$ of DNA, $10 \mathrm{mM}$ Tris- $\mathrm{HCl}, 1.5 \mathrm{mM} \mathrm{MgCl}_{2}, 50 \mathrm{mM} \mathrm{KCl}, 0.01 \%$ gelatin, each of the four deoxynucleoside triphosphates at a concentration of $200 \mu \mathrm{M}, 1.25 \mathrm{U}$ of Taq polymerase (Amersham International, Amersham, England), and each of the primers at a concentration of $5 \mu \mathrm{M}$. The reaction mixtures were overlaid with

TABLE 2. Primers used for PCR amplification and sequencing of RF Borrelia 16S ribosomal DNAs

\begin{tabular}{|c|c|c|c|c|}
\hline Primer & Sequence $\left(5^{\prime}\right.$ to $\left.3^{\prime}\right)$ & $\begin{array}{c}\text { Position } \\
\text { (E. coli numbering) }\end{array}$ & Designed for: & $\begin{array}{l}\text { Hybridization } \\
\text { temp }\left({ }^{\circ} \mathrm{C}\right)\end{array}$ \\
\hline \multicolumn{5}{|l|}{ PCR primers } \\
\hline $\mathrm{fD} 3^{a}$ & AGAGTTTGATCCTGGCTTAG & $8-27$ & Eubacteria & \\
\hline UniB & T(AC)AAGGAGGTGATCCAGC & $1582-1565$ & Eubacteria & \\
\hline $\mathrm{T} 50^{b}$ & GTTÁCGACTTCACCCTCCT & $1540-1522$ & Spirochetes & \\
\hline REC4 & ATGCTAGAAACTGCATGA & $659-675$ & RF Borrelia spp. & \\
\hline REC9 & TCGTCTGAGTCCCCATCT & 1191-1174 & RF Borrelia spp. & \\
\hline \multicolumn{5}{|c|}{ Sequencing primers } \\
\hline fD $3^{a}$ & AGAGTTTGATCCTGGCTTAG & $8-27$ & & 53 \\
\hline $250 \mathrm{~F}$ & CTTATTAGCTAGTTGGTAGG & $263-282$ & & 50 \\
\hline $250 \mathrm{R}$ & CСТАCCAACTAGCTAATAAG & $282-263$ & & 50 \\
\hline $400 \mathrm{~F}$ & GGAGCGACACTGCGTG & $414-429$ & & 50 \\
\hline $500 \mathrm{R}$ & CTGCTGGCACGTAATTAGCC & $548-529$ & & 57 \\
\hline $590 \mathrm{R}$ & ATATCCGCCTACTCA & $616-602$ & & 40 \\
\hline $800 \mathrm{~F}$ & ATTAGATACCCTGGTAG & $812-828$ & & 50 \\
\hline $800 \mathbf{R}$ & CTACCAGGGTATCTAAT & $828-812$ & & 50 \\
\hline $900 \mathrm{~F}$ & GAGTATGCTCGCAAGAGT & $887-904$ & & 50 \\
\hline 900R & ACTCTTGCGAGCATACTC & $930-913$ & & 50 \\
\hline $1050 \mathrm{~F}$ & TGTCGTCAGCTCGTG & $1095-1109$ & & 43 \\
\hline $1050 \mathrm{R}$ & CACGAGCTGACGACA & $1109-1095$ & & 43 \\
\hline $1200 \mathrm{~F}$ & TATGTCCTGGGCTACACACG & $1248-1267$ & & 57 \\
\hline $1200 \mathrm{R}$ & CGTGTGTAGCCCAGGACATA & $1267-1248$ & & 57 \\
\hline $\mathrm{rD}^{a}$ & AAGGAGGTGATCCAGCC & $1580-1564$ & & 50 \\
\hline
\end{tabular}

a Data from reference 40 .

${ }^{b}$ Data from reference 25. 
mineral oil $(50 \mu \mathrm{l})$. Amplification was carried out for 35 cycles consisting of denaturation at $93^{\circ} \mathrm{C}$ for $1 \mathrm{~min}$, annealing at $4^{\circ} \mathrm{C}$ below the denaturation temperature of the primer used for $1 \mathrm{~min}$, and extension at $72^{\circ} \mathrm{C}$ for $1 \mathrm{~min}$, and there was a final extension step consisting of $7 \mathrm{~min}$ at $72^{\circ} \mathrm{C}$.

Negative controls were included in all experiments. Reaction mixtures were prepared, and the samples were added with positive-displacement pipettes dedicated for the purpose. The PCR mixtures were prepared in a room where no DNA was handled.

The PCR products were detected by electrophoresis in a $0.8 \%$ agarose gel in TBE, followed by staining with ethidium bromide.

Direct sequencing of amplified fragments. The $r r s$ gene was sequenced by the method of Sanger et al. (35).

DNA amplification was performed by using the primer set consisting of primers fD3 and UniB, which was chosen on the basis of previously published $16 \mathrm{~S}$ ribosomal DNA sequences (40). The amplified product was purified by using Microspin S-400 HR columns (Pharmacia Biotech, Uppsala, Sweden) as recommended by the manufacturer.

The 5 ' fluorescein-labeled primers (Table 2) chosen were primers in conserved regions and were selected after the known sequences of the rrs genes of Borrelia species were aligned.

Sequencing reaction mixtures were prepared by using an Amplicycle sequencing kit (Perkin-Elmer Cetus, Norwalk, Conn.) and the conditions recommended by the manufacturer. Sequencing reactions were carried out under two distinct conditions, depending on the hybridization temperature requirements of the primers (Table 2). When the hybridization temperature was $>50^{\circ} \mathrm{C}$, an initial denaturation step at $95^{\circ} \mathrm{C}$ for $3 \mathrm{~min}$ was followed by 25 cycles consisting of denaturation at $95^{\circ} \mathrm{C}$ for $30 \mathrm{~s}$, annealing at the primer temperature for $30 \mathrm{~s}$, and extension at $72^{\circ} \mathrm{C}$ for $1 \mathrm{~min}$; the amplification reaction was completed by incubation for $5 \mathrm{~min}$ at $72^{\circ} \mathrm{C}$ to allow complete extension of the PCR products. When the hybridization temperature was $<50^{\circ} \mathrm{C}$, an initial denaturation step at $95^{\circ} \mathrm{C}$ for 3 min was followed by 30 cycles consisting of denaturation at $95^{\circ} \mathrm{C}$ for $30 \mathrm{~s}$ annealing at the primer temperature for $30 \mathrm{~s}$, and extension at $60^{\circ} \mathrm{C}$ for $2 \mathrm{~min} ; 10$ supplementary cycles of denaturation at $95^{\circ} \mathrm{C}$ for $10 \mathrm{~min}$ and extension at $60^{\circ} \mathrm{C}$ for $90 \mathrm{~s}$ were performed to increase polymerization.

A model 9600 thermocycler (Perkin-Elmer Cetus) and 6\% polyacrylamide gels in a model ALF automatic sequencer (Pharmacia) were used for the sequencing reactions.

Sequence alignments and phylogenetic inferences. Sequences were aligned both manually with VSM software V. 2.0 written by B. Lafay and R. Christen as described by Ruimy et al. (33) and with the multisequence alignment program Clustal V (14).

Phylogenetic relationships were analyzed by using three methods, and the results were compared. Parsimony analysis was performed with the PAUP program (phylogeny analysis using parsimony) (38). Evolutionary distances were computed with the Jukes-Cantor option (34) by using both the PHYLIP program package written by Felsenstein (11) and MEGA software (19). Phylogenetic trees were constructed by using the Kitsch + genetic distance algorithm from distance matrix data and by using the neighbor-joining method (34) in MEGA. The robustness of the topologies was estimated through 100 bootstrap replications. For the maximum-likelihood analysis, we used the PHYLIP program package.

Restriction polymorphism of the amplified 16S DNA fragment. On the basis of the sequence data, enzyme restriction sites that could be used to rapidly identify RF Borrelia species were chosen. Endonucleases MseI, BfaI (New England Bio-

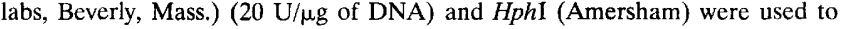
digest $10 \mu \mathrm{l}$ of PCR product.

Restriction fragments were resolved on a $10 \%$ acrylamide gel and/or a $16 \%$ acrylamide gel depending on the size of the expected DNA fragments. A molecular weight standard (pBR322 digested by HinfI) was included in each gel.

Nucleotide sequence accession numbers. The 16S DNA sequences of $B . m i$ -

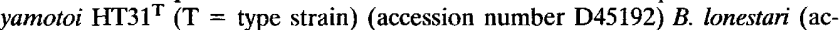
cession number U23211), and $B$. burgdorferi sensu stricto $B 31^{\mathrm{T}}$ (accession number X57404) were obtained from the GenBank database. The accession numbers for 16S ribosomal DNA sequences determined in this study are shown in Table 1.

\section{RESULTS}

Sensitivity and specificity of the PCR. The sensitivity of the PCR assay was assessed by using serial dilutions of cultures containing $10^{8}$ bacteria per $\mathrm{ml}$. When primers $\mathrm{fD} 3$ and UniB were used, the PCR detected 15 spirochetes. Primers fD 3 and T50 had a level of sensitivity of 500 bacteria. The sensitivity of the PCR with mouse sera was assessed by using $1 \mathrm{ml}$ of mouse blood spiked with $10^{8} \mathrm{~B}$. hermsii cells. The results obtained were comparable to those obtained with bacterial cultures.

The specificities of the diverse primer sets were determined by using DNAs from the RF Borrelia species listed in Table 1, DNAs from representative strains of each species belonging to B. burgdorferi sensu lato, DNAs from Serpulina hyodysenteriae,
Leptospira interrogans, and Treponema denticola, and DNAs from members of unrelated bacterial genera, including Helicobacter pylori, Campylobacter fetus, Streptococcus sp., Staphylococcus aureus, Bacillus sp., Listeria monocytogenes, Corynebacterium sp., Salmonella typhimurium, Yersinia enterocolitica, and Escherichia coli.

The use of primers $\mathrm{fD} 3$ and T50 resulted in amplification of a 1,487- or 1,489-bp DNA fragment specific for spirochetes, and the use of primers REC4 and REC9 led to amplification of a 523-bp DNA fragment specific for RF Borrelia species (data not shown).

Sequence analysis. Amplification of DNA with primers fD3 and UniB resulted in products that were about $1.5 \mathrm{~kb}$ long. These fragments were used to sequence the $r r s$ gene. The sequences corresponding to positions 8 to 1,576 ( $E$. coli numbering) were aligned manually and by using Clustal V software, with the same results. The levels of sequence similarity were calculated on the basis of 1,338 nucleotides common to all $r r s$ sequences. The levels of similarity between RF Borrelia species ranged from 97.7 to $99.9 \%$ (Table 3). The levels of sequence similarity between $r$ s sequences of RF Borrelia species and rrs sequences of $B$. lonestari and B. miyamotoi ranged from 96.4 to $98.1 \%$. The nine strains of $B$. crocidurae exhibited $100 \%$ sequence identity, as did three strains of $B$. duttonii. The highest level of similarity between "species" was the level of similarity between the sequences of $B$. crocidurae and B. duttonii (only one nucleotide difference). The lowest level of similarity, $97.7 \%$, was the level of similarity between the sequences of $B$. persica and $B$. anserina.

Sequences were analyzed by using both distance methods and a character state method (parsimony analysis). Figure 1 shows the phylogenetic relationships among various taxa as determined by the neighbor-joining method. The RF Borrelia species were subdivided into three major clusters. One cluster included $B$. crocidurae, $B$. duttonii, $B$. recurrentis, and $B$. hispanica. $B$. persica appeared to be on the border of this group. A second cluster comprised two main branches, with $B$. coriaceae, B. lonestari, and B. miyamotoi on one side and B. parkeri, $B$. turicatae, and $B$. hermsii on the other side. However, $B$. hermsii, although recently shown by DNA relatedness studies to be closely related to $B$. parkeri and $B$. turicatae (15), was on a separate branch. $B$. anserina was a single distantly related group. The results obtained when the Kitch + algorithm was used (data not shown) were consistent with the results obtained by other distance methods.

Figure 2 shows the $50 \%$ majority rule tree based on 12 trees obtained by using the parsimony analysis technique in the PAUP package. This tree was constructed by using the branchand-bound option with $B$. burgdorferi as an outgroup. In this analysis the same main phylogenetic groups were distinguished, except that $B$. persica was more peripheral than it was with the distance method. The same topology was obtained by using the maximum-likelihood method (data not shown).

Restriction fragment length polymorphism. The PCR primers fD3 and T50 generated 1,487- to 1,489-bp DNA fragments specifically from spirochete DNA. These PCR products were digested by $M s e \mathrm{I}, B f a \mathrm{I}$, and $H p h \mathrm{I}$. The results of an analysis of the restriction polymorphism are shown in Fig. 3.

After restriction by $\mathrm{MseI}$, six patterns were observed (Fig. 4). $B$. anserina, $B$. coriaceae, $B$. recurrentis, and $B$. persica each exhibited a specific pattern. $B$. duttonii, $B$. crocidurae, and $B$. hispanica exhibited a common pattern. The strains of $B$. hermsii, $B$. parkeri, and $B$. turicatae similarly exhibited a common pattern.

$B$. hermsii could be differentiated from $B$. parkeri and $B$. turicatae after restriction by $\mathrm{HphI}$ (Fig. 5). B. parkeri could also 

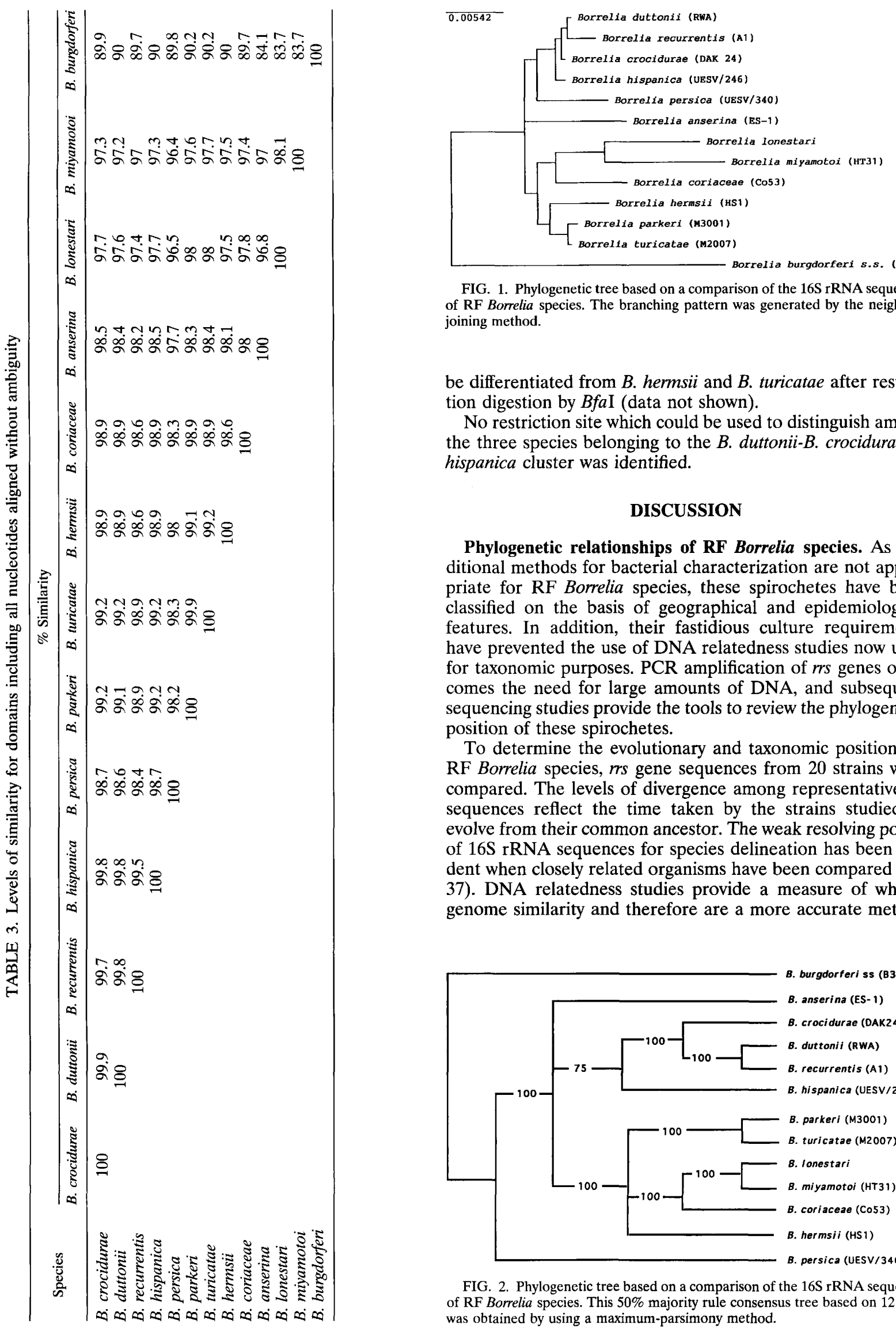

FIG. 1. Phylogenetic tree based on a comparison of the 16S rRNA sequences of RF Borrelia species. The branching pattern was generated by the neighborjoining method.

be differentiated from $B$. hermsii and $B$. turicatae after restriction digestion by $B f a \mathrm{I}$ (data not shown).

No restriction site which could be used to distinguish among the three species belonging to the $B$. duttonii-B. crocidurae- $B$. hispanica cluster was identified.

\section{DISCUSSION}

Phylogenetic relationships of RF Borrelia species. As traditional methods for bacterial characterization are not appropriate for RF Borrelia species, these spirochetes have been classified on the basis of geographical and epidemiological features. In addition, their fastidious culture requirements have prevented the use of DNA relatedness studies now used for taxonomic purposes. PCR amplification of $r$ rs genes overcomes the need for large amounts of DNA, and subsequent sequencing studies provide the tools to review the phylogenetic position of these spirochetes.

To determine the evolutionary and taxonomic positions of RF Borrelia species, rrs gene sequences from 20 strains were compared. The levels of divergence among representative $r$ rs sequences reflect the time taken by the strains studied to evolve from their common ancestor. The weak resolving power of 16S rRNA sequences for species delineation has been evident when closely related organisms have been compared (12, 37). DNA relatedness studies provide a measure of wholegenome similarity and therefore are a more accurate method

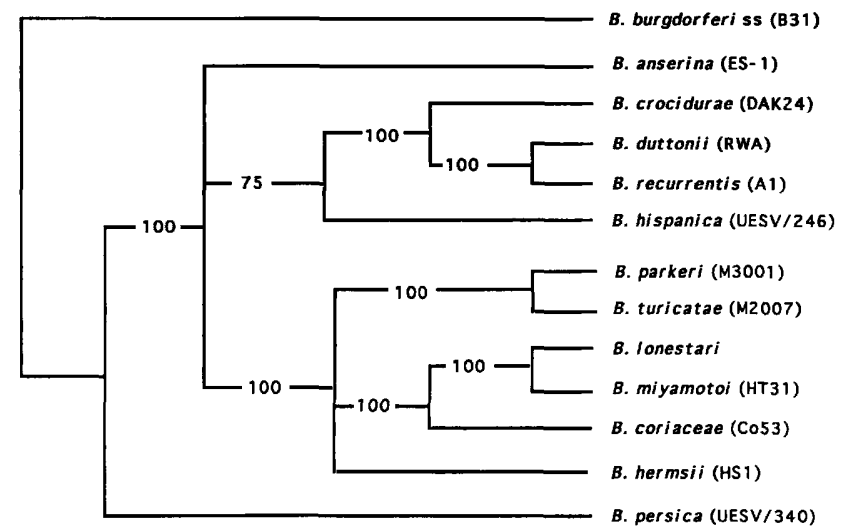

FIG. 2. Phylogenetic tree based on a comparison of the $16 \mathrm{~S}$ rRNA sequences of RF Borrelia species. This $50 \%$ majority rule consensus tree based on 12 trees was obtained by using a maximum-parsimony method. 


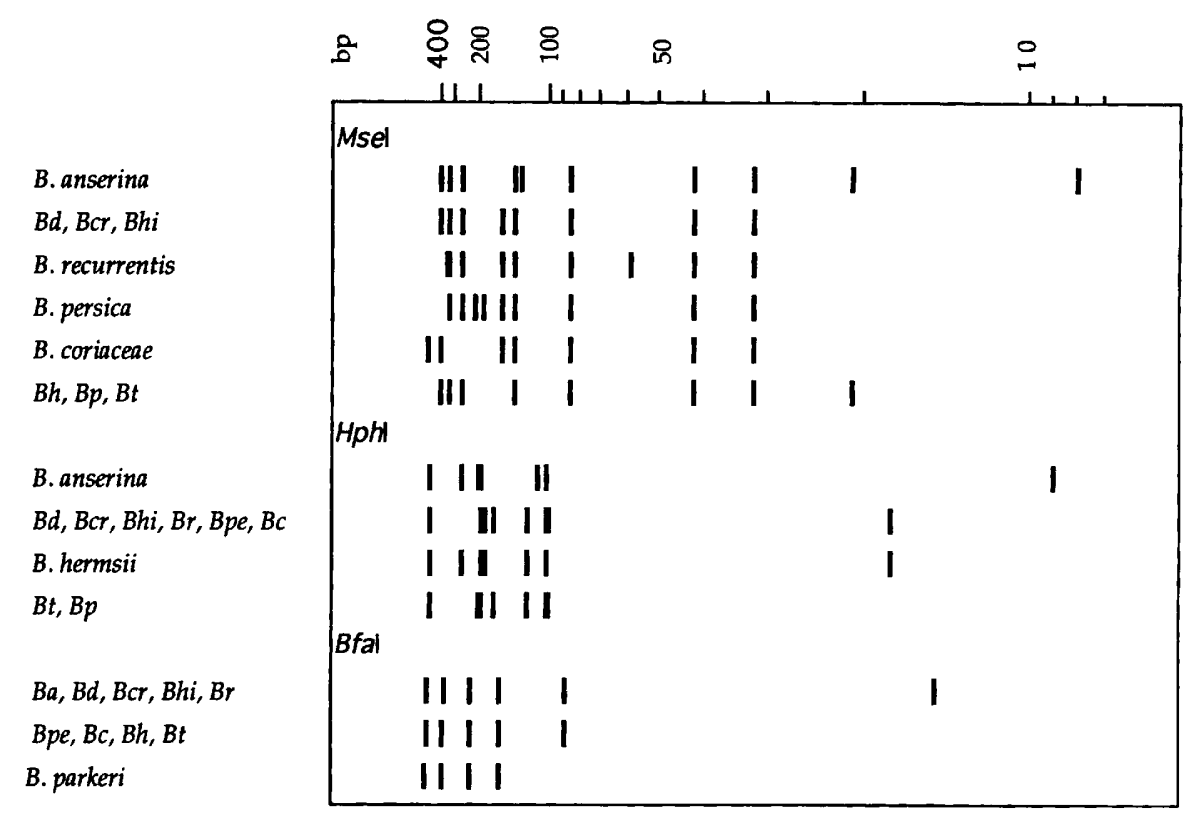

FIG. 3. DNA fragments obtained after restriction by $M s e \mathrm{I}, H p h \mathrm{I}$, and $B f a \mathrm{I}$ of the $r s$ gene amplified with primers fD3 and T50. Ba, B. anserina; $B d, B . d u t t o n i i ; B c r$, B. crocidurae; Bhi, B. hispanica; Br, B. recurrentis; Bpe, B. persica; Bc, B. coriaceae; Bh, B. hermsii; Bt, B. turicatae; Bp, B. parkeri.

for species identification (39). Although the two techniques mentioned above differ in their concepts, they are usually consistent in their results. However, it has been shown that if the level of 16S rRNA sequence similarity is greater than $97 \%$, there is no constant correlation between levels of sequence similarity and DNA reassociation values (37). Thus, the status of RF Borrelia species, at the species level, cannot be deduced from an analysis of rrs sequences alone. However, despite certain controversial or ambiguous results (8), ribosomal units and flanking region studies have proven to be useful for delineating, identifying, or confirming Borrelia taxonomic units (1, $20,22)$. For $B$. lonestari, rrs sequencing was the only basis for species definition (4).

Our results for the phylogenetic relationships of RF Borrelia species indicate that the taxonomy of the group should be revised. One distinct phylogenetic cluster comprises four species, $B$. crocidurae, $B$. duttonii, $B$. recurrentis, and $B$. hispanica. $B$. hispanica was previously placed in an intermediate position between $B$. duttonii and $B$. recurrentis (31). Interestingly, $B$. recurrentis could have evolved recently from a common ancestor with $B$. duttonii. Such a hypothesis has been proposed previously (32) on the basis of the common geographical endemicity of these organisms, their relatively high pathogenicities for humans, and successful experimental vector exchanges. It has even been suggested that each outbreak of louse-borne RF might be explained by the emergence of a new $B$. recurrentis strain from a tick RF Borrelia strain $(5,30)$. This suggestion is supported by the fact that tick-borne RF Borrelia strains can adapt to lice. However, the high number of nucleotide differences in $r r s$ between the two groups of strains does not support this hypothesis. The hypothesis that $B$. recurrentis and $B$. duttonii belong to a single species is not supported by our findings which revealed four nucleotide differences in the rrs sequences of these two taxa. $B$. recurrentis could represent a clone from the cluster consisting of $B$. crocidurae, $B$. duttonii, and $B$. hispanica, which has adapted specifically to a human vector, $P$. humanus. $B$. recurrentis might therefore be classified at the subspecies taxonomic level because of the clinical sever- ity and epidemic potential of louse-borne RF. The deeper branching of $B$. persica in the cluster consisting of $B$. crocidurae, $B$. duttonii, $B$. hispanica, and $B$. recurrentis may reflect distinct genospecies status.

In contrast, $B$. anserina was on a branch that was deeply separated from other Borrelia species. This may suggest that a putative ancestor of $B$. anserina was adapted to migratory birds, resulting in the distribution of clones throughout the world which later evolved into distinct taxa.

$B$. coriaceae is located in a heterogeneous cluster together with $B$. lonestari and $B$. miyamotoi, but the distances reflected by the branch lengths are large. $B$. coriaceae has been classified as a species that is distinct from $B$. hermsii, $B$. anserina, and $B$. crocidurae (17). Since the members of this group are widely distributed in different ecological niches, further study is

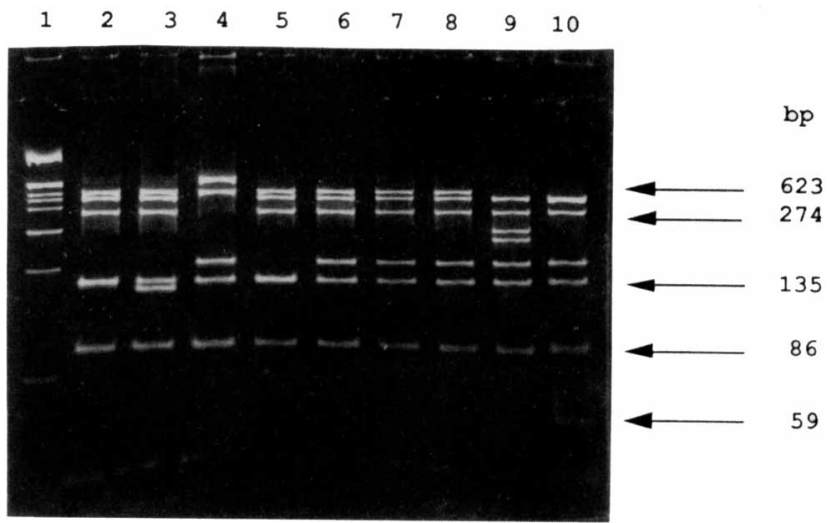

FIG. 4. Restriction patterns of RF Borrelia strains. DNAs amplified with primers fD3 and T50 were digested by MseI. The DNAs were electrophoresed on a $10 \%$ acrylamide gel, stained with bromide ethidium, and UV illuminated. Lane 1 , HinfI-digested $\mathrm{pBr}$ molecular weight marker; lane $2, B$. hermsii; lane $3, B$. anserina; lane $4, B$. coriaceae; lane $5, B$. parkeri; lane $6, B$. duttonii; lane $7, B$. crocidurae; lane $8, B$. hispanica; lane $9, B$. persica; lane $10, B$. recurrentis. 


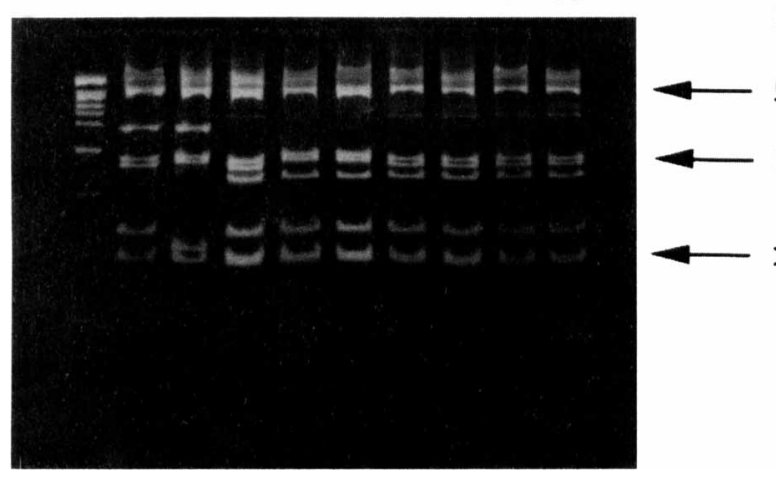

FIG. 5. Restriction patterns of RF Borrelia strains. DNAs amplified with primers fD 3 and T50 were digested by $H p h$ I. The DNAs were electrophoresed on a $16 \%$ acrylamide gel, stained with bromide ethidium, and UV illuminated. Lane 1, Hinfl-digested $\mathrm{pBr}$ molecular weight marker; lane 2, B. hermsii; lane 3, $B$. anserina; lane $4, B$. coriaceae; lane $5, B$. parkeri; lane $6, B$. turicatae; lane $7, B$. duttonii; lane $8, B$. crocidurae; lane $9, B$. hispanica; lane 10, B. persica.

needed to determine the exact taxonomic position of these organisms.

The taxonomic position of $B$. hermsii compared with the two other North American RF Borrelia species remains an open question. On the basis of DNA relatedness data, B. hermsii, $B$. parkeri, and $B$. turicatae have been assigned to the same genomospecies (15); despite this, they are still designated three separate species. Our phylogenetic analysis did not resolve the taxonomic status of $B$. hermsii. The levels of sequence similarity within this group (more than 99.1\%) are consistent with the results of DNA relatedness studies. However, the most parsimonious tree obviously supports separation of $B$. turicatae, the $B$. parkeri cluster, and $B$. hermsii. Clearly, more work will be required to determine the exact position of $B$. hermsii.

Genetic diversity and applications to diagnosis. In the past, diagnosis of RF was based on the detection of Borrelia species in blood smears and on the pathogenicity of these organisms for laboratory animals. Identification of the responsible Borrelia species was based on the geographical location where exposure occurred and the suspected tick vector. Because of cross-reactivity and antigenic variations in surface proteins of RF Borrelia species, serological tests are not appropriate. Some methods to identify cultivable strains have been developed $(26,36)$; however, the remaining noncultivable strains are poorly characterized. A simple diagnostic method for identifying RF Borrelia species is clearly necessary, and such a method would allow workers to study the epidemiological significance of the various species.

A PCR-based strategy is the best method for this. We deduced from the 16S ribosomal DNA sequences several sets of primers that allowed amplification of DNAs from RF Borrelia species both from culture medium and from biological samples. As a first step, bacteria can be identified as spirochetes by using the specific primers fD3 and T50 and as RF Borrelia species by using the specific primers REC4 and REC9. Then, restriction digestion of the $\mathrm{fD} 3-\mathrm{T} 50$ PCR product by three endonucleases separately allows rapid identification of the main RF Borrelia species. As previously shown for B. burgdorferi sensu lato strains (29), the use of restriction site polymorphism of PCR products from rrs genes provides a simple, specific, and rapid way to identify RF Borrelia species without the need to culture the organisms.

\section{ACKNOWLEDGMENTS}

We thank M. M. J. Lapierre, M. Gentilini, C. Lapresle, B. Dupont, J. Fleury, and J. F. Trape for supplying strains, J. C. Jacques, O. Poupel, and A. Boutonnier for technical assistance, B. Paster and F. E. Dewhirst for providing the sequence of primer T50, and M. Gouy and J. Thioulouse for supplying the njplot software.

We thank the Pasteur Institute and the Programme Hospitalier de Recherche Clinique 1993 Assistance Publique de Marseille for supporting this work.

\section{REFERENCES}

1. Adam, T., B. Graf, U. Neubert, and U. B. Göbel. 1992. Detection and classification of Borrelia burgdorferi by direct sequencing of 16S rRNA amplified after reverse transcription. Med. Microbiol. Lett. 1:120-126.

2. Baranton, G., D. Postic, I. Saint Girons, P. Boerlin, J. C. Piffaretti, M. Assous, and P. A. D. Grimont. 1992. Delineation of Borrelia burgdorferi sensu stricto, Borrelia garinii sp. nov., and group VS461 associated with Lyme borreliosis. Int. J. Syst. Bacteriol. 42:378-383.

3. Barbour, A. G. 1984. Isolation and cultivation of Lyme disease spirochetes. Yale J. Biol. Med. 57:521-525.

4. Barbour, A. G., G. O. Maupin, G. J. Teltow, C. J. Carter, and J. Piesman. 1996. Identification of an uncultivable Borrelia sp. in the hard tick Amblyomma americanum: possible agent of a Lyme disease-like illness. J. Infect. Dis. 173:403-409.

5. Burgdorfer, W. 1976. The epidemiology of the relapsing fevers, p. 191-200. In E. R. C. Johnson (ed.), Biology of parasitic spirochetes. Academic Press, New York.

6. Burgdorfer, W., A. G. Barbour, S. F. Hayes, J. L. Benach, E. Grundwald, and J. P. Davis. 1982. Lyme disease: a tick-borne spirochetosis? Science 216: 1317-1319.

7. Canica, M. M., F. Nato, L. du Merle, J. C. Mazie, G. Baranton, and D. Postic. 1993. Monoclonal antibodies for identification of Borrelia afzelii sp. nov. associated with late cutaneous manifestations of Lyme borreliosis. Scand. J. Infect. Dis. 25:441-448.

8. Clayton, R. A., G. Sutton, P. S. Hinkle, Jr., C. Bult, and C. Fields. 1995. Intraspecific variation in small-subunit rRNA sequences in GenBank: why single sequences may not adequately represent prokaryotic taxa. Int. J. Syst. Bacteriol. 45:595-599.

9. Cutler, S. J., D. Fekade, K. Hussein, K. A. Knox, A. Melka, K. Cann, A. R. Emilianus, D. A. Warrell, and D. J. M. Wright. 1994. Successful in vitro cultivation of Borrelia recurrentis. Lancet 343:242.

10. Felsenfeld, O. 1965 . Borreliae, human relapsing fever, and parasite-vector host relationships. Bacteriol. Rev. 29:46-74.

11. Felsenstein, J. 1990. PHYLIP-phylogeny inference package (version 3.3). Department of Genetics, University of Washington, Seattle.

12. Fox, G. E., J. D. Wisotzkey, and P. Jurtshuk, Jr. 1992. How close is close: 16S rRNA sequence identity may not be sufficient to guarantee species identity. Int. J. Syst. Bacteriol. 42:166-170.

13. Fukunaga, M., Y. Takahashi, Y. Tsuruta, O. Matsushita, D. Ralph, M. McClelland, and M. Nakao. 1995. Genetic and phenotypic analysis of Borrelia miyamotoi sp. nov., isolated from the ixodid tick Lxodes persulcatus, the vector for Lyme disease in Japan. Int. J. Syst. Bacteriol. 45:804-810.

14. Higgins, D. G., and R. Sharp. 1989. Fast and sensitive multiple sequence alignments on a microcomputer. CABIOS 5:151-153.

15. Hyde, F. W., and R. C. Johnson. 1984. Genetic relationship of Lyme disease spirochetes to Borrelia, Treponema, and Leptospira spp. J. Clin. Microbiol. 20:151-154.

16. Izraeli, S., C. Pfleiderer, and T. Lion. 1991. Detection of gene expression by PCR amplification of RNA derived from frozen heparinized whole blood. Nucleic Acids Res. 19:6051.

17. Johnson, R. C., W. Burgdorfer, R. S. Lane, A. G. Barbour, S. F. Hayes, and F. W. Hyde. 1987. Borrelia coriaceae sp. nov.: putative agent of epizootic bovine abortion. Int. J. Syst. Bacteriol. 37:72-74.

18. Kawabata, H., T. Masuzawa, and Y. Yanagihara. 1993. Genomic analysis of Borrelia japonica sp. nov. isolated from Ixodes ovatus in Japan. Microbiol. Immunol. 37:843-848.

19. Kumar, S., K. Tamura, and N. Masatoshi. 1993. MEGA: molecular evolutionary genetics analysis, version 1.01. The Pennsylvania State University, University Park.

20. Marconi, R. T., and C. F. Garon. 1992. Identification of a 3rd genomic group of Borrelia burgdorferi through signature nucleotide analysis and 16S rRNA sequence determination. J. Gen. Microbiol. 138:533-536.

21. Marconi, R. T., D. Liveris, and I. Schwartz. 1995. Identification of novel insertion elements, restriction fragment length polymorphism patterns, and discontinuous 23S rRNA in Lyme disease spirochetes: phylogenetic analyses of rRNA genes and their intergenic spacers in Borrelia japonica sp. nov. and genomic group 21038 (Borrelia andersonii sp. nov.) isolates. J. Clin. Microbiol. 33:2427-2434.

22. Marconi, R. T., L. Lubke, W. Hauglum, and C. F. Garon. 1992. Speciesspecific identification of and distinction between Borrelia burgdorferi genomic 
groups by using $16 \mathrm{~S}$ rRNA-directed oligonucleotide probes. J. Clin. Microbiol. 30:628-632.

23. Meier, J. T., M. I. Simon, and A. G. Barbour. 1985. Antigenic variation is associated with DNA rearrangements in a relapsing fever Borrelia. Cell 41:403-409.

24. Nicolle, C., L. Blaizot, and E. Conseil. 1913. Etiologie de la fievre récurrente. Son mode de transmission par les poux. Ann. Inst. Pasteur (Paris) 27:204 225.

25. Paster, B., and F. E. Dewhirst. 1995. Personal communication.

26. Picken, R. N. 1992. Polymerase chain reaction primers and probes derived from flagellin gene sequences for specific detection of the agents of Lyme disease and North American relapsing fever. J. Clin. Microbiol. 30:99-114.

27. Plasterk, R. H. A., M. I. Simon, and A. G. Barbour. 1985. Transposition of structural genes to an expression sequence on a linear plasmid causes antigenic variation in the bacterium Borrelia hermsii. Nature (London) 318:257263.

28. Postic, D., M. V. Assous, P. A. D. Grimont, and G. Baranton. 1994. Diversity of Borrelia burgdorferi sensu lato evidenced by restriction fragment length polymorphism of $n f(5 S) m l$ (23S) intergenic spacer amplicons. Int. J. Syst. Bacteriol. 44:743-752.

29. Ralph, D., D. Postic, G. Baranton, C. Pretzman, and M. McClelland. 1993. Species of Borrelia distinguished by restriction site polymorphisms in $16 \mathrm{~S}$ rRNA genes. FEMS Microbiol. Lett. 111:239-243.

30. Rodhain, F. 1976. Borrelia et fièvres récurrentes: aspects épidémiologiques actuels. Bull. Inst. Pasteur 74:173-278.

31. Rodhain, F. 1989. Les fièvres récurrentes dans l'oeuvre de Charles Nicolle. Med. Mal. Infect. 19:768-772.

32. Rodhain, F., O. Poupel, and J. C. Jacques. 1991. Les Borrelia d'ornithodores de la région afro-tropicale: intérêt et limites des essais de protection croisée chez la souris. Bull. Soc. Pathol. Exot. 84:30-45.

33. Ruimy, R., V. Breittmayer, P. Elbaze, B. Lafay, O. Boussemart, M. Gauthier, and R. Christen. 1994. Phylogenetic analysis and assessment of the genera Vibrio, Photobacterium, Aeromonas, and Plesiomonas deduced from smallsubunit rRNA sequences. Int. J. Syst. Bacteriol. 44:416-426.

34. Saitou, N., and M. Nei. 1987. The neighbour-joining method: a new method for reconstructing phylogenetic trees. Mol. Biol. Evol. 4:406-425.

35. Sanger, F., S. Nicklen, and A. R. Coulson. 1977. DNA sequencing with chain-terminating inhibitors. Proc. Natl. Acad. Sci. USA 74:5463-5467.

36. Schwan, T. G., K. L. Gage, R. H. Karstens, M. E. Schrumpf, S. F. Hayes, and A. G. Barbour. 1992. Identification of the tick-borne relapsing fever spirochete Borrelia hermsii by using a species-specific monoclonal antibody. J. Clin. Microbiol. 30:790-795.

37. Stackebrandt, E., and B. M. Goebel. 1994. Taxonomic note: a place for DNA-DNA reassociation and $16 \mathrm{~S}$ rRNA sequence analysis in the present species definition in bacteriology. Int. J. Syst. Bacteriol. 44:846-849.

38. Swofford, D. L. 1992. PAUP: phylogenic analysis using parsimony, version 3.0. Illinois Natural History Survey, Champaign.

39. Wayne, L. G., D. J. Brenner, R. R. Colwell, P. A. D. Grimont, O. Kandler, M. I. Krichevsky, L. H. Moore, W. E. C. Moore, R. G. E. Murray, E. Stackebrandt, M. P. Starr, and H. G. Trüper. 1987. Report of the Ad Hoc Committee on Reconciliation of Approaches to Bacterial Systematics. Int. J. Syst. Bacteriol. 37:463-464.

40. Weisburg, W. G., S. M. Barns, D. A. Pelletier, and D. J. Lane. 1991. 16S ribosomal DNA amplification for phylogenetic study. J. Bacteriol. 173:697703. 